\title{
La experiencia mística durante el climaterio: Un acercamiento desde la endocrinología antropológica
}

\author{
Elvira M. MELIÁN \\ Especialista en Endocrinología y Nutrición \\ Máster en Ciencias Históricas \\ emelian@telefonica.net
}

Recibido: 1.06 .2013

Aceptado: 18.11.2013

\section{RESUMEN}

Durante siglos la urdimbre entre lo empírico y lo creencial ha favorecido la identificación de la posmenopáusica con arquetipos antagónicos de transformación espiritual positivos o negativos. Entre los primeros encontramos el éxtasis místico, cuya elevada prevalencia durante el climaterio puede vincularse desde la endocrinología antropológica a cambios previos ligados al apagamiento ovárico en los ejes lácteo, óseo y adrenal que atenúan el vínculo femenino terrenal en favor del espiritual.

Palabras clave: Endocrinología antropológica, Menopausia, Mística, Lactancia, Androginia, Osteoporosis.

Mystic ecstasy in climateric woman:

an approach since the anthropologycal endocrinology

\begin{abstract}
For centuries the interweave of empirical and faith-based beliefs has favored an identification of postmenopausal woman with positive or negative archetypes of spiritual transformation. The former includes mystical ecstasy, whose prevalence during menopause can be related by anthropological endocrinology to previous transformations linked to the ovarian shutdown in the mammary, bone and adrenal axes that disturb the balance between earthy matters and spiritual life in favor of the latter.
\end{abstract}

Key words: Anthropological endocrinology, Menopause, Mystic, Lactancy, Androgen, Osteoporosis.

\section{INTRODUCCIÓN}

Desde la antropología médica se ha considerado genéricamente que "sociedad y cultura" pueden modular la enfermedad en tres formas: primera, definiendo las condiciones de normalidad y anormalidad, en definitiva su misma existencia, segunda, regulando las prácticas y hábitos causantes de la misma, y tercera, favoreciendo su aparición en condiciones sociales restrictivas (Martínez, 2011:68). Como hija del primer mecanismo, la menopausia ha basculado desde una secular omisión a encendidos elogios actuales sobre sus teóricas bondades a través de un 
prolongado intervalo en que ha sido considerada patológica. En el trayecto se ha pasado de tratar indiscriminadamente a menopáusicas asintomáticas (WHI, 2002: $321)^{1}$ a hacerlo por mínimo tiempo y mínima dosis efectiva a mujeres con calidad de vida severamente afectada por síntomas vasomotores (Warren, 2007: 219). A esta medicalización/des-medicalización no es ajena una cultura donde religión, autoridad y sugestión han delineado secularmente este hito de la biología femenina.

Definido como "los cambios biológicos, psicológicos y socioculturales asociados a la involución gonadal" (Hunter, 2007: 261) durante el climaterio nos enfrentamos a una realidad biológica heterogénea (Burger, 2010:257) , $^{2}$ y el ancestral desconocimiento de su fisiopatología ha favorecido la identificación secular de la climatérica real con arquetipos femeninos antónimos (Melián, 2011:185). En consecuencia aún superponiéndose alegóricamente al apogeo existencial (Rojas, 2002: 1607) ${ }^{3}$ y personificando la estabilidad psíquica (Ripa, 2007) ${ }^{4}$, tan tarde como en 1948 Simone de Beauvoir habla de una "edad peligrosa, caracterizada por ciertos disturbios orgánicos, pero lo que les da su importancia es el valor simbólico que revisten" (Beauvoir, 1986: 359). En la primera mitad del siglo XX, descubierto el papel intermediario de las hormonas entre los estímulos sensoriales y los órganos internos, se las consideraba reguladoras de las emociones y a un proceso derivado del envejecimiento ovárico favorecedor del desequilibrio mental (Marañón, 1927). En las fronteras de esta escala de subordinación encontramos textos jurídicos coetáneos defendiendo una responsabilidad penal atenuada para delincuentes menstruantes, climatéricas y embarazadas por sometimiento de las "anomalías éticas a las hormónicas"(Jiménez de Ansúa, 1928: 209).

\footnotetext{
${ }^{1}$ Los hallazgos de 2002 sobre los efectos deletéreos de la terapéutica hormonal sustitutiva del Women's Health Initiative Study (WHI) marcaron el punto de inflexión.

${ }^{2}$ La menopausia abarca en sus extremos desde los 40 a los 60 años, si asumimos como edad media de la menopausia los 51 años y una dispersión entre los 45 y 55 años. Así la menopausia propiamente dicha definida como los primeros 12 meses tras la última menstruación culmina una peri-menopausia previa de años de evolución en el que ya están presentes signos endocrinos, biológicos y clínicos que anuncian la senescencia gonadal, y es seguida por la pos-menopausia que a su vez es temprana hasta cumplir los 5 primeros cinco años sin reglas y tardía desde entonces hasta la muerte.

${ }^{3}$ Para la Hieroglyphica, primer diccionario de símbolos el ser humano vive entre los 42 y 49 años el periodo de máximo desarrollo del conjunto espíritu-físico y entre los 49 y 56 la perfección máxima de inteligencia y lengua con un físico conservado.

${ }^{4}$ Obra original publicada por primera vez en 1616 y ampliamente difundida por Occidente desde el siglo XVII. La filosofía se define como una matrona climatérica de "venerable rostro, colmada de años pero viva de color, aunque gastada y demacrada y que conserva su vigor y fortaleza contra todas las adversidades manteniendo el equilibrio de su mente frente a todo trastorno o mutación de su ánimo".. En razón de su "experiencia, capacidad de discernimiento, máxima memoria, mente sólida y juicio sano" es imagen asimismo economía, autoridad, doctrina, academia, meditación, matemática, memoria, nobleza, persuasión o paciencia. Es más, Ripa identificaba de forma explícita la virilidad "edad más perfecta del hombre" como una mujer adulta y madura de 50 años.
} 
El misticismo puede considerarse una desviación del arquetipo de buscadora espiritual que ha acompañado a la menopausia durante siglos de opresión religiosa (Marañón, 1925: 273). Beauvoir aseguraba que ésta crea en la mujer la ilusión de una "vida nueva" al dividir la vida femenina en dos:

"se abre otro tiempo y lo aborda con fervor de conversa que se ha convertido al amor, a la vida de Dios, al arte y a la humanidad, entidades en las cuales se pierde y magnifica. Ha muerto y ha resucitado, considera la tierra con ojos que han penetrado los secretos del más allá, y cree volar hacia cimas inmaculadas" (Beauvoir, 1986: $365)$.

Este proceso en mitad de una vida asentada en la inmanencia conllevaba para ella el riesgo de sucumbir al poderoso ascendiente de "sectas religiosas, espiritistas, profetas y curanderos y por todos los charlatanes" (Beauvoir, 1986: 364) y era la causa de que la mayor parte de estigmatizadas de la iglesia católica fueran "mujeres que han pasado, término medio, la edad de la menopausia”.

En 1925 Marañón señalaba ya la complejidad de una "edad crítica" donde:

"el sistema endocrino-vegetativo adquiere habitualmente un grado de tensión funcional que le hace particularmente apto para la receptividad emocional y como esta circunstancia fisiológica coincide con una circunstancia social paralela, esto es, con el aumento de las agresiones emocionales en este periodo de la vida, el organismo es afectado profundamente por las noxas afectivas" (Marañón, 1925: 104)

Pese a los avances médicos, su concepto de "umbral de emoción" o "ventana de vulnerabilidad" ligado a la menopausia responsable de que "las agresiones emocionales cercan, pues al espíritu, cuando es más vulnerable" (Marañón, 1925: 121) persiste de forma textual en artículos científicos de la máxima actualidad (Freenman, 2010: 823) $)^{5}$. En la exhaustiva literatura médica contemporánea las alteraciones anímicas ligadas al climaterio se perciben como resultado de la interacción entre factores emocionales y vasomotores (Bromberger, 2011: 609) ${ }^{6}$, y las fluctuaciones estrogénicas de la transición menopáusica como gatillo para la somatización de crisis existenciales en poblaciones predispuestas (Soares, 2007: 1285). Desde la endocrinología antropológica la prevalencia de misticismo en esta edad se simbólicamente sustenta en la mudanza hormonal que acompaña a la liberación reproductora: el aumento de andrógenos devuelve a la mujer a una

\footnotetext{
${ }^{5}$ En este artículo podemos leer en términos textuales "menopausal transition is a window of vulnerability".

${ }^{6}$ Como ocurre durante la edad fértil con el síndrome de disforia premenstrual o la depresión postparto.
} 
androginia primordial, su leche se torna en sabiduría nutricia, y la osteoporosis atenúa la densidad de sus huesos aprestándola para el vuelo del espíritu. Esto es, la fémina adquiere cualidades metafóricamente atribuidas a la plenitud espiritual.

\section{SUSTRATO SOCIO-BIOLÓGICO DE LA EXPERIENCIA MÍSTICA: NEUROPÉPTIDOS Y NEUROTRANSMISORES CEREBRALES}

Beauvoir señalaba como modelo de misticismo peri-menopáusico a Teresa de Jesús, cuyos primeros éxtasis pasados los 43 años resultaron en la fundación de su primer convento en 1562 y el segundo en 1567, contando 47 y 52 años, respectivamente."Santa Teresa" es el resultado del ahínco de la Contrarreforma primero en perseguirla y luego en enaltecer su figura pero lo cierto es que, como bien señala el teólogo Hans Kung,

"ni en el antiguo ni en el nuevo testamento existe un ideal de oración interior o de oración de corazón, ni se encuentra exhortación alguna a observar, describir y analizar vivencias y estados místicos, ni aparece ninguna clase de escala mística que culmine en el éxtasis, ni se subraya un tipo de oración que requiera unas dotes religiosas especiales" (Kung, 2002: 63).

La experiencia mística no deja de ser uno entre los ubicuos y ancestrales procedimientos para alcanzar un estado alterado de conciencia: ayuno, penitencia, drogas vegetales, venenos, o ritos iniciáticos (Varios autores, 2005) ${ }^{7}$. Hoy sabemos que el denominado "cerebro social" resulta de la interacción entre genética individual y los efectos de la colectividad sobre el desarrollo cerebral temprano (Ebstein, 2010: 831), y que en esta compleja red las hormonas dependientes de género modulan aspectos insospechados como ética, desordenes psiquiátricos y neuroteleología (Pascal, 2008: 111).

La impronta de la biología en la expresión individual de cualquier fenómeno social incluido los estados alterados de conciencia es determinante (Adolphs, 2010: 752). De hecho existe un sustrato físico común entre la experiencia mística y otros procesos mentales asociados con hiper-religiosidad como la esquizofrenia, los trastornos obsesivo-compulsivos, o la epilepsia del lóbulo temporal (Fred, 2006: 500). Concretamente los éxtasis teresianos se han identificado como crisis epilépticas del

${ }^{7}$ Clásicamente en nuestras fronteras se ha llegado al éxtasis religioso por tres vías con una fenomenología corporal notoriamente diferente: la purgativa con secuelas físicas de la penitencia, la iluminativa con manifestaciones derivadas de la autosugestión y la de unión mística prerrogativa de los santos, con un lenguaje no asociado a la oración y la meditación. 
lóbulo temporal (García Albea, 2003: 879) ${ }^{8}$, si bien el reciente hallazgo de dimetiltriptamina (DMT) endógena en la glándula pineal humana abre nuevas hipótesis sobre su génesis. Este producto, que en su forma farmacológica se ha utilizado durante siglos por culturas indígenas y modernas como psicodélico, afecta la percepción sensorial actuando sobre un receptor específico (Fontanilla, 2009: 934). Y existe una sorprendente similitud entre las fases de una experiencia con esta droga y las descripciones de Teresa de Jesús hace sobre sus arrobamientos (De Jesús，1963: 127 y sig. $)^{9}$.

\section{SUSTRATO ENDOCRINO-ANTROPOLÓGICO DE LA EXPERIENCIA MÍSTICA: LA SOFÍA ANDRÓGINA Y ALADA}

Independientemente de sus bases biológicas el misticismo sucede reiteradamente al apagamiento previo de tres ejes hormonales con cenit durante la vida fértil: lácteo, gonadal y óseo.

La leche humana ha sido un elemento natural venerado desde tiempo inmemorial (Newman, 2009) ${ }^{10}$ : medicina para numerosos males (Ferrándiz, 2001), símbolo de amor filial (Luna, 2002), protagonista de los Diez Mandamientos (Frazer, 1975), o elemento sagrado en las más primitivas tribus (Frazer, 1951). En Egipto se llamará nodriza al preceptor del príncipe como amamantador del espíritu, en Roma se abandonarán los niños en la columna lactaria para ser adoptados (Soles, 2011,) y no en vano una Sara centenaria amamantara a Isaac durante 5 años. En la covada lactaria, entendida como legitimación de parentesco a través de un mecanismo de

\footnotetext{
${ }^{8}$ Comienzo inesperado, duración breve, contenido psíquico o sensorial, alucinaciones complejas generalmente religiosas con autoconciencia de las mismas y sentimientos de goce y felicidad.

${ }^{9}$ En el primero se habla de una experiencia rápida, con visiones que oscurecen la realidad ordinaria, sensación subjetiva de muerte, de dejar de latir y respirar, ralentización corporal, sensación de dejar de tener un cuerpo, trascender tiempo y espacio para pasar a ser parte del "continuo universal", seguida de reunificación a los 5-12 minutos, asombro total, euforia y vibración residual hasta vuelta posterior al estado normal en una hora thttp://es.wikipedia.org/wiki/Dimetiltriptamina. Por su parte Teresa habla de una experiencia que "dura poco", "en libertad en una hora o menos", donde es levantada y suspendida "lanzada de sí" ; similar a los "tránsitos de la muerte salvo que trae consigo gran contento", sensación subjetiva de dejar de respirar y latir, "se me quitan todos los pulsos", "el cuerpo queda como muerto" con los "sentidos suspendidos", "manos muy yertas, canillas muy abiertas"; visiones muchas veces intelectuales que oscurecen la realidad aunque " pocas veces se pierde el sentido y no deja de entender y oír como cosa de lejos"; un "desasimiento extremo" al retornar en sí.

${ }^{10}$ Aparecen diosas lactantes en esculturas prehistóricas, en Egipto destaca Hathor, diosa madre con cabeza de vaca y Nut, diosa celeste que aplaca la sed con la lluvia de su leche, y la leche de Hera crea la vía Láctea en la mitología pagana.
} 
suplantación, se otorga simbólicamente a las diosas nodrizas un origen similar a las diosas de la fertilidad (Casas, 1926). De hecho aún hoy en numerosas culturas islámicas se mantiene una forma de covada en la que el parentesco cultural de la madre de leche aporta a la lactante-nodriza poder económico y social, y se hace extensivo al padre de leche como señor de misma condicionando prohibiciones legales como un parentesco natural (Soles, 2011). La fortaleza de este vínculo durante el periodo de apogeo de misticismo y pseudo-misticismo en nuestras fronteras se dibuja nítidamente en las recomendaciones de Huarte de San Juan en 1603,

"traer a casa a la nodriza 4-5 meses antes del parte y darle de comer los mismos manjares de que usa la preñada, para que tenga lugar de gastar la sangre y demás humores que ella tenía, hechos de los demás alimentos que ante había comido, y para que el niño luego en naciendo mame la misma leche de que se mantuvo en el vientre de la madre, o a lo menos hecha de los mismo manjares" (Huarte de San Juan, 1953)

Hasta que en el siglo XIX la medicina separe reproducción y nutrición la lactancia ha constituido un vínculo natural entre personas junto a la concepción, el embarazo y el parto (Soles, 2011: 26). Ya los clásicos consideraban leche y flujo menstrual como dos manifestaciones de una misma esencia procedente de las venas expulsadas por dos orificios naturales; la menstruación nutría al hijo en el útero y la lactancia en la vida postnatal,

“(...) en circunstancias normales las hembras en período de lactancia no tienen menstruación, ni tampoco pueden concebir; y si conciben la leche cesa, porque la naturaleza de la leche y de las menstruaciones es la misma. La naturaleza no puede ser tan productiva como para bastarse en ambas funciones, sino que si la secreción se produce en un sitio, es forzoso que falte en otro, a no ser que ocurra algo violento y contrario a la norma" (Ferrándiz 2001:249)

La base fisiopatológica de esta afirmación es clara: durante la lactancia la prolactina inhibe la secreción de las hormonas responsables del ciclo menstrual produciendo un estado de infertilidad transitorio y suprimiendo la menstruación (Melmed, 2008). Pero frente al carácter impuro de la sangre menstrual (Melián, 2011) la leche ha simbolizado la maternidad espiritual como alternativa a la material, en especial durante el climaterio. Tanto en el Antiguo Testamento como en los Hechos Apócrifos de los Apóstoles la postmenopáusica estéril parece portadora de un grado, por así decirlo, para llegar a Dios; las primeras son sobradamente conocidas ${ }^{11}$, y de las segundas nunca se mencionan eventuales hijos, como si ambos terrenos,

${ }^{11}$ Dentro del grupo de climatéricas estériles a las que Iahvé elige recordemos a Santa Ana y San Joaquín, en el protoevangelio de Santiago ((II, I); Raquel, madre de José, segunda mujer de Jacob (Génesis 30: 9), o Ana, mujer de El cana y madre de Samuel (Sam1, 20) entre otras. 
espiritualidad y fecundidad estuvieran enfrentados (Cerro Calderón, 2003). Conforme el catolicismo resta valor a la vida terrenal la leche se torna en don del espíritu. Así Teresa de Jesús habla en Camino de Perfección de almas aplicadas a los pechos divinos para gozar y del alma como un niño de pecho (Varios autores, 2005: 123) ${ }^{12}$, y una de las formas predominantes de representar el Eros místico durante la Contrarreforma es la lactación mística de San Bernardo donde la virgen coloca su pecho en la boca transfiriéndole el conocimiento divino (Stoichita, 1995 :135).

La Gran Madre representada inicialmente como diosa paleolítica de senos hipertrofiados se transforma en madre espiritual tanto en Occidente como en Oriente conforme la transformación mistérica boca/aliento, aliento/soplo, soplo/palabra $(\log o s)$ y $\operatorname{logos} /$ espíritu relacione este último con su origen nutricio y matriarcal (Newman, 2009: 73) ${ }^{13}$. En esta metamorfosis la leche, uno de los tres misterios ancestrales de transformación sanguíneos femeninos, mantiene su simbolismo de eterno retorno y vínculo. Así la Sofía/Sabiduría se nos presenta en el libro de los Proverbios del Antiguo Testamento como partícipe de la naturaleza divina antes de la creación del mundo (Prov. 8, 1-31) para asumir posteriormente los papeles de emanación de la gloria de Dios y su esposa (Piñero, 2007)

“La Sofía ama y salva. Y su corazón es a la vez alimento y sabiduría. Ya no interesada primariamente, como la Gran madre del estado elemental, en el lactante, el niño o la persona inmadura, sino que con divinidad del Todo busca personas completas que han recorrido todo el trayecto" (Newman, 2009: 324).

Por su parte la diosa Loto, útero de todo lo creado, consorte y energía de Visnú, se irá transformando en símbolo de la sabiduría trascendental. Como el espíritu Santo y en lo que constituye una excepción para las divinidades hindúes esta diosa tiene alas (Zimmer, 2008: 95).

La menopáusica tiene otros dos atributos, osteoporosis y virilización, que la acercan simbólicamente al cenit de la especie (Durant, 2005). La célebre buscadora espiritual contemporánea Sara Maitland las convierte en sus cuentos en piratas, pájaros o seres mitológicos que ponen en práctica deseos largamente aplazados durante la vida fértil (Maitland, 2003). Para ello utiliza la osteoporosis ligada a la deficiencia de estrógenos como metáfora de ascenso y liberación estableciendo correspondencias entre la menor densidad ósea de la climatérica y los huesos de las aves cuyas cavidades llenas de aire le permiten volar. El ave tiene un carácter andrógino en la cultura patriarcal representando el orden celestial masculino frente a

\footnotetext{
12 Desde otros muchos escenarios no cristianos el éxtasis místico se ha descrito como una regresión al estado de lactancia.

${ }^{13}$ En el Riga Veda Brahmanes Pati el logos se convierte en vaca, la diosa madre elemental.
} 
la serpiente como madre tierra y, ya sea como ave Fénix griego, Bennu egipcio o Garuda del hinduismo y el budismo es también símbolo de renacimiento, purificación, y vida inmortal (Zimmer, 2008: 77)

Cuando San Pedro protesta en el apócrifo de Santo Tomás por las preferencia de Jesús hacia María Magdalena, "que se aleje Mariham de nosotros, pues las mujeres no son dignas de la vida! el Mesías le tranquiliza: "Mira, yo me encargaré de hacerla macho, de manera que también ella se convierta en un espíritu viviente, idéntico a vosotros los hombres: pues toda mujer que se haga varón entrará en el reino de los cielos" (T114) (Apócrifos, 705). Gracias al aumento de secreción de andrógenos suprarrenales que se mantiene hasta la menopausia tardía (Lasley, 2001: 467; Macconell, 2012: 658) la climatérica accede a la androginia primordial consustancial a todas las cosmologías, teologías y mitologías (Libbis, 2001), en lo que ya Plinio y Aristóteles definieron como "virilización relativa"" (Marañón, 1925: 287). Estos cambios le permiten ascender de categoría social en numerosas culturas primitivas tras convertirse en un interludio entre lo masculino y lo femenino (Cabello, 1995: 131). Incluso la Iglesia institucional, reacia a las prácticas eremíticas femeninas, las admitirá de forma ocasional cuando las mujeres superen los 40 años de edad ${ }^{15}$ por estar liberadas de las limitaciones de la vida fértil y la maternidad (Barbeito, 2002: 185). No en vano las tres religiones monoteístas han asentado para el número 40 a través de los siglos el simbolismo de renacimiento espiritual en el acervo cultural de Occidente (Brandes, 1995: 27) ${ }^{16}$.

Lamentablemente en la doble cara de los mitos el andrógino arquetípico con connotaciones simbólicas de perfección, sabiduría y plenitud convive con el andrógino histórico, rechazado socialmente como una "usurpación profana" del mito (Libbis, 2011: 168). Durante la Edad Moderna, época de apogeo místico, los arquetipos corporeizados de postmenopáusicas virilizadas son un ejemplo de esta esquizofrénica dualidad. Por una lado encontramos viviendo en olor a santidad tras

\footnotetext{
${ }^{14}$ Marañón distinguía un virilismo menopáusico psíquico y uno somático no siempre ligados pues en un caso encontramos "una transformación viril más o menos acentuada, el aumento de la corpulencia, el brote de vello, la gravedad de la voz, sin que en nada se alteren los rasgos de su feminidad" y en el otro "el estado psíquico se transforma en el mismo sentido y "la mujer adquiere una energía, una agresividad que antes no tenía, y que la acercan a la norma psicológica del varón"."

${ }^{15}$ Es el caso de las Sinodales de Pamplona promulgadas en agosto de 1590.

${ }^{16}$ Las 4 simbologías del 40 son: 1 , multitud o fuerza como las cuarenta mil personas en la batalla de Jericó (José, 4:13); 2, numeroso o mucho, como los cuarenta días y cuarenta noches del Diluvio (Génesis 7:4); 3, renacimiento espiritual como Mahoma cuando se le apareció el arcángel Gabriel o Moisés cuando abandonó el desierto y 4, simbología de purificación, sacrificio o transición donde retornamos al ayuno de Moisés o Jesús en el desierto y entramos de lleno en el terreno femenino con la cuarentena tras dar a luz.
} 
iniciar una vida anacoreta en plena menopausia (Cortijo Ocaña, 2003: 21) ${ }^{17}$ a Catalina de Cardona, cuyas fuentes aseguran que tomaban por eunuco, tuvo "ánimo y pecho de varón", "aborrecía mucho el parecer mujer" y prefería ser etiquetada de "varonil, varoníssima o seguidora de Elías" (De San Gabriel, sin fecha); por otro las desventuradas brujas no dejan de ser seres ambiguos sexualmente, peludos, acnéicos y con abundantes elementos viriloides (Libbis, 2001: 174) ${ }^{18}$. Seres que por cierto volaban, aunque fuera en escoba.

\section{EPÍLOGO}

Como principio "pasivo" de la naturaleza las mujeres constituimos un arquetipo simbólicamente complejo; en nuestro prisma imperfecto, como Eva o Elena, representamos impulso y sentimentalismo, mientras en nuestro prisma ascendente, como Sofía o María, personificamos intelecto y moral (Cirlot, 203: 320). El cambio hormonal ligado al fallo ovárico ha conducido a que la climatérica encarne secular y simultáneamente arquetipos de transformación espiritual positiva (virgen, sabia, compañera) o negativa (bruja, loca, prostituta, hechicera) (Libis, 2001: 174). En su origen encontramos una cultura popular y un desconocimiento científico que han llevado a considerar la menopausia casi como un proceso alquímico.

Para la alquimia el hermafrodita es el símbolo de la unión perfecta de los contrarios femenino y masculino y se representa por dos mitades hombre y mujer junto al mercurio filosófico en forma de alas o pájaro (Priesner, 2001). Alinear metafóricamente a la mística en este esquema permite comprender el auge de estas experiencias durante un estado postmenopáusico asexual, liviano y liberado de las obligaciones reproductivas.

\section{BIBLIOGRAFÍA}

ADOLPHS, R. (2010): "Conceptual changes and directions in social neuroscience", Neuron $65,752-767$

BARBEITO, I. (2002) “Mujeres eremitas y penitentes”. Via Spiritus 9, 185-215.

\footnotetext{
${ }^{17}$ Podemos leer entre otras cosas que "como a la madre Teresa Dios le dio toda la perfección a la que pueden imitar y llegar las mujeres, así a la madre Cardona le dio todo el valor y rigor de espíritu de Elías, a que tendrán bien que hacer en llegar los más arriscados hombres".

${ }^{18}$ Acomodables en "el primer grado de las mujeres frías y húmedas en tercer grado: avisadas, de mala condición, con voz abultada, de pocas carnes, verdinegra, vellosa y fea y, de joven claro, muy mala de engendrar" (Huarte de San Juan, 1953:49).
} 
BEAUVOIR, SIMONE (1986): El segundo sexo. La experiencia vivida. Buenos Aires, Siglo XXI, 359.

BOYER, P. (2008): "Evolutionary perspectives on religion", Ann. Rev. Anthropology 37, 111-130.

BRANDES, S. (1995): “¿Qué significa cumplir los cuarenta? Cultura y crisis a la mitad de la vida". Revista de dialectología y tradiciones populares 50, 2, 27-50.

BROMBERGER, J. (2011): "Mood and menopause: findings from the study of women's health across the nation (SWAN) over 10 years", Obstet Gynecol Clin N Am 38, 609-625.

BURGER, H. (2010): "Hormonal changes in the menopause transition", Rec. Progres Horm Res 57, 257-275.

CABELLO, P. (1995): "La mujer en torno a la menopausia en el arte y la cultura indígena americanas", Anales del Museo de América 3,131-144.

CASAS, E. (1926): La covada y el origen del totemismo. Madrid, Católica Toledana.

CERRO CALDERON, G. (2003): Las mujeres de los Hechos Apócrifos de los Apóstoles. Málaga, ed. Clásicas.

CIRLOT, V. (2003): Diccionario se símbolos. Madrid, Ciruela.

CORTIJO OCAÑA, A. (2003): "Vida de la madre catalina de Cardona por fray Juan de la miseria. Un texto hagiográfico desconocido del siglo XVI (Bancroft Library, UCB, Fernán Núñez Collection, vol. 143)" Dicenda: Cuadernos de Filosofía Hispánica 21, 21-34.

DURANT, G. (2005): Las estructuras antropológicas del imaginario. Méjico. Fondo de Cultura Económica.

EBSTEIN, R. (2010): "Genetic of human social behaviour", Neuron 65, 831-844

FERRÁNDIZ, C. (2001): "Dioscórides (Bestiario) de A. Laguna". Madrid,. Medusa.

FRAZER, J. (1951): La Rama Dorada. Magia y Religión. México, Fondo de Cultura Económica.

FRAZER, J. (1975): El folklore en el Antiguo Testamento. Méjico, Fondo de cultura económica.

FREENMAN, E. (2010): "Associations of depression with the transition to menopause", Menopause 17, 823-827.

FONTANILLA, D. (2009): "The hallucinogen N, N-Dimethyltryptamine (DMT) is an endogenous Sigma-1 receptor regulator", Science 323, 934-937.

GARCÍA ALBEA, E. (2003): "La epilepsia de Teresa de Jesús”. Rev. Neurol 9, 879887.

DE SAN GABRIEL. De la buena mvger doña Chatalina de Cardona heremita carmelita descalza y fundadora del convento heremítico de nra. Señora del Socorro y de otros por su medio fundados. Los discursos que, carmelita descalzo, su confessor y deboto hijo meditaba,... Madrid, Biblioteca Nacional ms. 4213 fols. $12 \mathrm{r}$ y $17 \mathrm{v}$.

HUARTE DE SAN JUAN (1953) Examen de los Ingenios, Biblioteca de Autores Españoles, tomo XLV Madrid, Ed. Atlas.

HUNTER, M. (2007): "Bio-psycho-socio-cultural perspectives on menopause", Best practice \& Research Clinical Obstetrical and Gynecology 21, 2, 261-274. 
DE JESUS, T.1963) Obras completas. Madrid, Aguilar.

JIMENEZ DE ANSUA, L. (1928): "Libertad de amar y derecho a morir". Historia Nueva, 209-212

KÚNG, H. (2002): La mujer en el cristianismo. Madrid, Mínima Trotta.

LASLEY, B. (2011): "Adrenal androgens and the menopause transition". Obs Gym Clin North Am, 467-475.

LIBIS, J. (2001): El mito del andrógino. Madrid, Siruela.

LUNA, A. (2002): Libro de las claras e virtuosas mujeres Valladolid, Maxtor.

MACCONELL, D. (2012): "Menopause transition stage specific changes in circulating androgens", Menopause, 658-663.

MAITLAND, S. (2003): On becoming a fairy godmother. London, Maia Press Limited.

MARAÑON, G. (1925): La edad crítica. Madrid, Ruiz Hermano ed.

MARAÑON, G. (1927): "Patología e higiene de la emoción", Revista de la Residencia de Estudiantes 11 (i), 1-7.

MARTÍNEZ HERNÁNDEZ, A. (2011): Antropología médica. Teorías sobre la cultura, el poder y la enfermedad. Madrid, Anthropos.

MELIÁN, ELVIRA M. (2011): "En la barca de Caronte (la menopausia o la gran transformación)", Feminismo/s 18,185-202

MELMED, S. (2008): “Anterior pituitary". en Kronenberg HM, Melmed S, Polonsky KS, Larsen PR. (eds.) Williams, Textbook of Endocrinology. 11th ed. Philadelphia, PA, Saunders Elsevier.

NEUMAN, E. (2009): La gran madre. Una fenomenología de las creaciones femeninas de lo inconsciente. Madrid, Trotta.

PÉREZ DE AYALA, R. La Esfera 21/7/ 1928

PIÑERO, A. (2007): Los cristianos derrotados. Madrid, Edaf.

PREVIC, F. (2006): "The role of extra personal brain systems in religious activity". Consciousness and Cognition 15,500-539.

RIPA, C. (2007): Iconología. Madrid, Akal/Arte y Estética.

ROJAS RODRIGUEZ, A. (2002) "Los "Hieroglyphica" de Piero Valeriano y su recepción en España durante el siglo XI", Humanismo y pervivencia del mundo clásico: homenaje al profesor Antonio Fontán, 3, 1607-1612.

SOARES, C. (2007): "Menopausal transitions and depression: who is at risk and how to treat it? Expet Rev" Neurotherapeutics 7, 1285-1293

SOLES, E. (2011): Lactancia y parentesco. Una mirada antropológica. Madrid, Anthropos.

STOICHITA, V. (1995): Visionary experience in the golden age of Spanish, London, Reaktion books.

VARIOS AUTORES (2005): La experiencia mística y los estados de conciencia Madrid, Kairós.

VARIOS AUTORES (2006): Los evangelios apócrifos. Madrid, Biblioteca de Autores Cristianos.

WARREN, M. (2007): "Historical Perspectives in postmenopausal hormonal therapy: defining the right dose and duration”, Mayo Clin Proc, 219-226. 
WRITING GROUP FOR THE WOMEN'S HEALTH INITIATIVE INVESTIGATIONS: El WHI (Women's Health Initiative Study). (2002) "Risk and benefits of estrogens plus progestin in healthy postmenopausal women". JAMA 288: 321-333.

ZIMMER, H. (2008): Mitos y símbolos de la India. Madrid, Siruela. 